\title{
Constructive Assessment Method for Simulator Training
}

\author{
Laura Marcano Tiina Komulainen \\ Department of Electronic Engineering, Oslo and Akershus University College of Applied Sciences (HiOA), Norway \\ \{Laura.Marcano, Tiina.Komulainen\} @hioa.no
}

\begin{abstract}
Industrial operator assessment is a very controversial subject in the scientific community, as determining the most suitable, objective and effective means of giving feedback on an operator's performance is a great challenge. This paper presents a proposal on assessment methods for simulation training. The development is based on the results from simulator training courses held at Oslo and Akershus University College of Applied Sciences (HiOA) from 2010 to 2014. The results and course evaluation were analyzed to identify where new methods could be applied that would lead to improvement. The method proposed consists of an automatic assessment procedure, which will give feedback to the simulator course participants during the simulator session and help the students to achieve the learning outcomes. The proposed method will be tested in the simulator training courses at HiOA in spring 2017 and the results will be presented in a later paper.
\end{abstract}

Keywords: assessment, performance, operator, feedback, students, learning outcome

\section{Introduction}

\subsection{Simulator training and performance assessment challenges}

The evaluation of operators' performance represents a significant challenge for the process industry, as the appropriate assessment of operators' performance is of great importance to ensuring the right competencies and safe plant operations.

A recent study in the Norwegian oil and gas industry (Komulainen and Sannerud, 2014) reveals that only $30 \%$ of the respondents take exams after the simulation courses. The evaluation of the simulator trainee performance is based on the instructor's verbal feedback during the scenario and the instructor's verbal assessment after the scenario.

The automatic assessment tools available require the implementation of a specific sequence of actions for each scenario. The main criticism of automatic assessment is the high implementation and maintenance workload of the scenarios, the difficulty of implementing just one optimal sequence for complex scenarios, i.e. there can be many good alternative solutions, and the interpretation of operators' learning outcomes, competencies and skills from the figures generated by the automatic assessment system. Thus, the use of automatic assessment tools is not widespread in the Norwegian oil and gas industry.

Virtual laboratories i.e. complex process simulators, are important learning tools in modern engineering education; they are relevant to industrial practice, they facilitate collaborative, active learning among the students, and they are time and cost effective (Coble et al., 2010; Corter et al., 2011; Edgar et al., 2006; Komulainen and Løvmo, 2014; Martin-Villalba et al., 2008; Rasteiro et al., 2009; Rutten et al., 2012; Wankat, 2002).

Dynamic process simulators have been used as an additional learning tool at HiOA since 2010 (Komulainen and Løvmo, 2014). Our experience shows that simulator training provides industrially relevant practice for large student groups. However, in order to provide prompt assessment of learning outcomes at an individual level, an effective personal feedback and assessment tool is required.

Both industrial and academic experience on simulator training indicate a need for effective automatic assessment measures. The challenge in developing such a tool is to avoid too deterministic measures (i.e. scenario-specific sequences), and to ensure the clarity and measurability of the learning outcomes.

\subsection{Introduction to the proposed work}

The simulation module is built up using the six categories of the didactic relation model: learning goals, content, learning process, learning conditions, settings, and assessment. These categories are relative to each other i.e. if changes are made in one of the categories this will lead to changes in the other categories (Bjørndal and Lieberg, 1978; Hiim and Hippe, 1998).

Thus, the assessment of the simulation module has to be directly related to the learning goals of the simulation module. In the following, we suggest measuring the theoretical knowledge using key performance indicators (KPI) and to measure practical competencies using operator performance indicators (OPI).

1) Key performance indicators (KPI): The evaluation of the performance of any process is a matter of high 
priority, as it is necessary to determine how efficient the process is and whether it is being executed as optimally as possible. In the research of Manca et al. (2012), it is indicated that from the 1980s, the scientific community became aware of the industry's need for performance assessment. Therefore, it was necessary to establish quantitative indicators that could help to measure the production efficiency of a process; these indicators are known as Key Performance Indicators (KPIs).

Key Performance Indicators express the performance of a whole process; they measure the performance of all types of equipment that form a plant and of the entire plant itself (Lindberg et al., 2015). In the industry sector, performance indicators based on human factors are called operator performance indicators (Manca et al., 2012), which, conversely to KPIs require a more complex evaluation due to their implicit human attributes.

2) Operator performance indicators (OPI): Kluge et al. (2009) carried out extensive research on different training methods used for process control simulators. They explain several of the goals of simulator training, some of which are summarized below:

- Lead the trainees to an understanding of physical processes, the overall operation of the plant, and system functionality.

- Start-up and shut-down procedures.

- Procedural knowledge for normal plant operation and the use of checklists.

- Operators should be able to improvise and adapt to the contingencies of abnormal events.

The goals of simulator training are thereby to meet an overall main objective: efficient operator performance.

From the research of (Nazir et al., 2015), several relevant factors can be recognized that can be considered as operator performance indicators. In the process industry, there are two kinds of operators, Control Room Operators (CROPs) and Field Operators (FOPs). One of the most important features of the teamwork between these two kinds of operators is communication. Effective collaboration between CROPs and FOPs leads to the necessary actions to avoid accidents. Therefore, one important OPI is effective communication. Another OPI that can be associated with the teamwork between CROPs and FOPs is the accomplishment of tasks. Process safety is determined by different capabilities that must be associated with operators. Hence, these capabilities are related to OPIs as well: the ability to interpret the available information; ability to identify abnormalities; understanding the process in terms of operation, equipment, and instruments; being able to interact with different teams and deal with abnormal and escalating situations. Another specific characteristic of great importance, which is also related to OPIs, is time. The time taken to execute certain tasks and more specifically, the time taken to deal with abnormal or emergency scenarios, as this is a direct reflection of the responsiveness and attention skills of the operator (Nazir et al., 2015).

Similarly, based on the research conducted by (Nazir et al., 2012) on situation awareness in industrial plants, Manca et al. (2012) identified some characteristics that are related to the concept of OPI. These characteristics are:

- level of knowledge of the fundamentals of the process;

- the role played by the streams involved in the process;

- the ability to run the process under new conditions;

- the ability to deal with abnormal situations;

- the ability to establish a safety culture and

- the ability to coordinate actions.

There is a common factor in the last four studies referred to above, namely the understanding of the process; this can be considered as one of the most important OPIs, as good performance is based on good knowledge of what is done. Kluge et al. (2009) suggested that "knowledge of how to operate the plant to achieve certain goals can lead to good performance". Nevertheless, it is becoming a challenge for operators to obtain good and sufficient knowledge of the processes they operate due to the great advancements in automation, which are more and more complex and lead to information overload and difficulties related to human machine interface (Nazir et al., 2014; Zou et al., 2015).

Nazir et al. (2013) mention the relevant role played by the execution of an appropriate performance evaluation of the operators. The authors suggest that a correct assessment of the operators is also part of a welldesigned training method, in order to reduce the number of accidents occurring in the industrial sector and their impact. It is indicated in the study, that the assessment procedure should be completely objective, in order to guarantee consistency, quantitative assessment, repeatability, and neutrality. Therefore, the assessment process must be automatic. In order to do so, the specific characteristics that the system will evaluate must be identified. These are: OPIs, KPIs and help requirement analysis. In their article, they present an example of the methodology of performance assessment for a catalytic inject process and a $\mathrm{C} 3 / \mathrm{C} 4$ splitter. The operator performance indicators evaluated in this case were: Reaction time, Identification ability, Self-dependence, Attentiveness, Multitask handling, Voice communication, Identification ability, Recalling ability, and Situation handling.

Within the same context, Manca et al. (2012) conducted research where they indicate the importance of the assessment of the training performance of CROPs. The authors indicate that developing these evaluations represents a challenge, because the assessment is based on performance indicators related to 
human beings and therefore on their intrinsic complexity, which leads to subjective evaluations by the instructors. Because of this, it is very important to develop assessment methods based on quantitative values and not just qualitative appreciation, so the assessment can be as unbiased as possible. In the research, they present a hierarchy scheme with different categories and classifications that form the overall CROP mark. The structure is used as a basis for determining the importance and the weighting of each OPI for the operator assessment. Each OPI is assigned a different value according to its place in the hierarchy using the Analytic Hierarchy Process (AHP). The authors suggested this method in order to overcome the drawbacks related to the subjectivity of the trainers.

Characteristics of the OPIs: One of the main features of OPIs is that they are intrinsically related to human factors as they are linked with the assessment of human beings; this is precisely what makes their evaluation so complex. However, Manca et al. (2012) explain that OPIs are not only based on human factors, there are other parameters that also contribute to the OPIs' definition, such as consistency and association.

\section{Materials and Methods}

\subsection{Software tools for simulator training}

The dynamic simulation software used is K-Spice ${ }^{\circledR}$ by (Kongsberg, 2016). K-Spice ${ }^{\circledR}$ is a modular simulation tool for oil and gas unit operations based on first principles physics, chemistry, and engineering.

Exercise Manager is an automatic assessment software product for the K-Spice tool. The simulation model used for the study is a generic oil and gas production simulator model that consists of a threestage, three-phase oil and gas separation train, the utility systems, and emulated control and safety systems. An overview of the plant is given in Figure 1. More details on the model and the assessment tool are given by (Komulainen and Løvmo, 2014).

\subsection{Software tools for simulator training}

1) Sample selection: All the participating students attend two different courses at HiOA.

2) Data collection: The anonymous data collected included a multiple-choice questionnaire and the numerical results of the final exam. The questionnaire included several questions about simulators as an additional learning tool, and was evaluated on a 5-point scale. The questionnaire was given to the students at the end of the simulation module. The exam results were obtained from the teacher, who prepares and grades the final exam.

3) Data analysis: Questions on whether simulation enhanced the students' learning outcomes were evaluated on a 5-point scale, the percentages for "agree" and "highly agree" are presented in the following. The

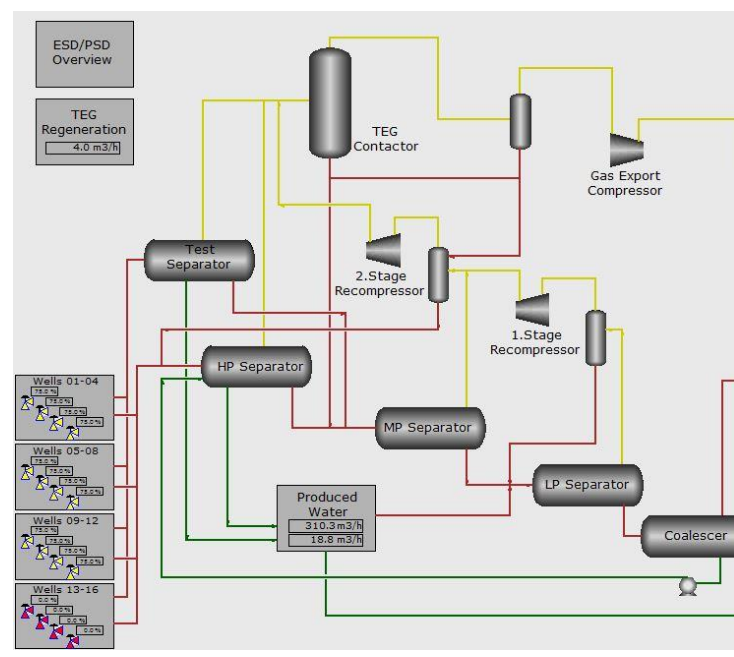

Figure 1. Overview of the large-scale oil and gas production plant model.

marks of the simulation task(s) in the final exam were compared to the average marks in the final exam.

\section{Teaching and Learning in Simulator Training}

\subsection{Teaching and learning in simulator training at HiOA}

The simulator training at HiOA follows the industrial briefing - simulation - debriefing structure. During the two-hour briefing session, the teacher presents the simulator, the dynamic trends, and the tasks in a classroom for all the students. For the four-hour simulation sessions, the students are divided into larger groups. Typically, the students work on familiarization tasks (60-75 min) before the simulation scenarios (2-3h). The students start writing a preliminary simulation report during the simulation session, and spend approximately two hours afterwards to finish the report before the debriefing workshop. In the two-hour debriefing workshop, the students compare and discuss the simulation results in new groups of four students. At the end of the workshop, the teacher facilitates the summarization of the simulation results and of the overall experience on a whiteboard. The total time spent on one simulation training module is 7-10 hours.

The teacher explains the basics of the simulation tasks and gives a simulation demonstration during the introduction lecture. During the simulation sessions, the teacher has an instructor role, only providing help if the student group cannot find the solution themselves. In the workshop, the teacher is a facilitator, setting a framework for the group discussions on the simulation results and guiding the final plenary presentation of the results. The teacher gives the students feedback during the simulation sessions and the workshop, and grades the simulation reports. 
The simulation tasks aim to enhance social interaction in small groups while the main focus is for each student to learn by doing the simulation tasks and reporting at their own pace. Discussions on the simulation results are encouraged during the simulation sessions and during the debriefing workshop, i.e. learning from peers and through reflection.

\subsection{Current feedback and evaluation methods for simulator training}

There is no feedback during the simulation scenarios if the students do not ask the instructor questions. During the debriefing workshop, students get feedback from their peers.

The learning outcomes of the simulation module are measured using the results of the formal final exam.

The students evaluate the simulation module as part of the compulsory report using a multiple-choice questionnaire.

\subsection{Experience with simulator modules at HiOA}

In the following, the results of two different simulation modules, namely laboratory distillation system and industrial large-scale oil production facility, are presented. The simulation modules were taught to two groups of chemistry students and two groups of electrical engineering students over a period of four years.

The simulation modules were taught in three sessions using briefing-simulation-debriefing (i.e. lecturecomputer exercise-workshop) structure, which is typical for industrial simulator training. At the end of the simulation module, the students deliver their simulation reports in groups and present their results in groups at the workshop. The instructor for all simulator modules was the main teacher of the course.

The undergraduate chemical engineering course (fall 2010-spring 2011, 20 chemistry students) where mandatory dynamic distillation simulator exercises were given prior to laboratory experiments: $95 \%$ of the chemistry students agreed that simulation enhanced their learning. The average final exam result was $56 \%$, whereas the simulation tasks received an average mark of $70 \%$ (Komulainen et al., 2012).

The results for the undergraduate chemical engineering course (fall 2011-spring 2012, 20 chemistry students) were similar, $90 \%$ of the students agreed that simulation enhanced their learning. The average final exam result was $43 \%$, whereas the four simulation tasks received an average mark of $47 \%$. The reason for the generally lower exam scores in 2012 was the change of exam type from written to multiple-choice with similar calculation task (Komulainen, 2013).

The undergraduate course in dynamic systems (fall 2013, 60 electrical engineering students) resulted in $97 \%$ of students agreeing that simulation exercises increase their understanding of process dynamics in fluid systems. The average final exam result was 59\%, whereas the simulation tasks received an average of $48 \%$. One possible explanation for the low score of the simulation tasks was an unclear simulation chart (Komulainen and Løvmo, 2014).

The following year (fall 2014, 60 electrical engineering students) in the exam, the simulation chart was prepared with better resolution and clearer marking of the axes. The final exam result was $58 \%$ on average and the simulation task received an average mark of $54 \%$.

In the final exam, the students scored higher than average when the simulation exercise was related to a practical laboratory experiment, and lower than average when the simulation results were not applied afterwards. One possible explanation is that group work without direct feedback might lead to misconceptions.

The students' evaluation of the simulation module and the students' evaluation of their own learning from simulation were very positive for all the groups. The students learn to use industrially relevant tools and their understanding of industrial processes increases.

\subsection{Conclusions based on previous experiences}

Utilization of industrial large-scale simulators enables students to gain additional skills: industrially relevant process knowledge, and teamwork skills. However, the feedback and assessment system needs to be developed further in order to clearly indicate whether the students have reached the learning goals.

\section{Suggested Practices}

\subsection{Suggested effective assessment method for simulator learning}

The main goal of the simulation module is to help the students obtain a better understanding of complex processes and to see the application of theoretical equations and concepts by means of realistic examples and methods. Therefore, there is always an academic commitment to develop revised strategies and procedures that can lead to improvement of the learning outcome.

The aim of this project is to improve the learning outcome of the practices that apply to the simulation module at HiOA. Hence, it is important to be able to measure the knowledge of the students before and after taking the simulation module. This will enable us to make a more formal and reliable evaluation of the benefits of using simulators as a learning tool. In order to achieve this, a diagnostic test based on the required conceptual knowledge about the subject in question should be applied.

The tasks connected to the simulation course have, until now, been based on the students making certain changes to the system and then analyzing the results. 
The proposed idea is to add a new section to the simulation module, where the changes in the system will be pre-established, and the students should be able to recognize the abnormal situation and fix it.

The abnormal situation scenarios will be developed using a simulation program associated with the subject or topic of interest. In the case of the present project, which is based on industrial process control, the K-Spice Exercise Manager will be used. The students will have to run different simulation scenarios and observe the possible deviations from normal operations. They will see on the screen the corresponding alarm(s) that will lead them to the source(s) of the abnormal situation. Once the students recognize the problem, they should correct it based on their knowledge of the process. Once the scenario task is completed, a short assessment report will be delivered. The assessment report will be based on strategic performance indicators so that the evaluation is objective and unbiased. The total assessment will correspond to a main performance indicator, which is the Abnormal Situation Management (ASM). This main indicator at the same time may depend on different complementary factors as can be seen from Figure 2.

In Figure 2, the effectivity of the trainee refers to the total time required by the student to fully complete the task. The oil production must be monitored since this is the main goal of the industrial process related to the simulation module, and abnormal situations must be solved as soon as possible and efficiently, in order to avoid major oil production losses. It is also very important to monitor the environmental indicators, such as the flare flow rate or the produced water composition, since abnormal situations can also have serious repercussions for the environment. Another significant

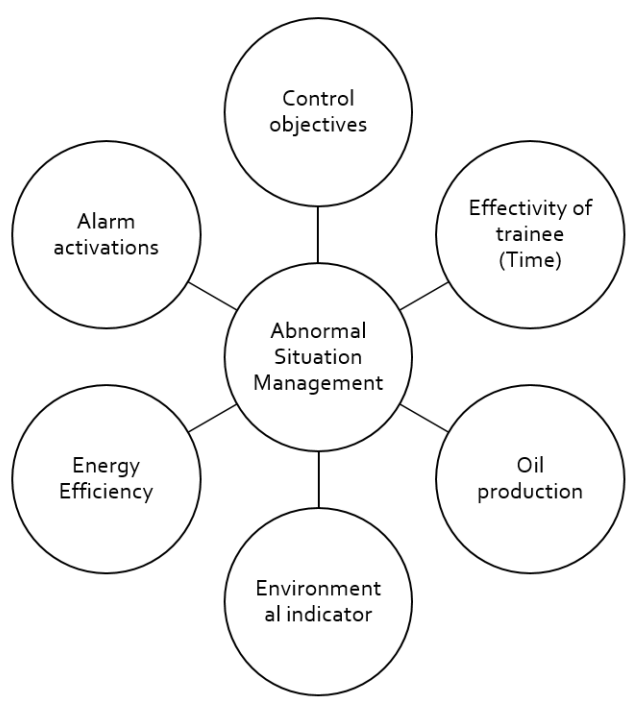

Figure 2. Main performance indicator and complementary factors. factor is the energy efficiency of the process, which is analyzed through the total power consumption of the plant.

Every abnormal situation in industrial processes is reported by an alarm. The scenarios will be designed such that the problem presented in each task will constantly activate an alarm until the student solves the problem. A record of how long the alarm is active before the problem is solved is indicative of the performance of the student. Finally, the control objectives will be evaluated by the calculation of the integral of the squared error for the controller $\mathrm{XC}$, which indicates how well the problematic controller was tuned, if this is the case. The following equation will be used to determine the total evaluation of the main performance indicator ASM.

$$
A S M=\frac{r_{O P} \cdot w_{O P}}{r_{O P, \max }}+\sum_{i}\left(\frac{r_{i, \max }-r_{i}}{r_{i, \max }-r_{i, \min }}\right) \cdot w_{i}
$$

Where the first term of the equation is related to the oil production (OP), $\mathrm{r}_{\mathrm{OP}}, \mathrm{w}_{\mathrm{OP}}$ and $\mathrm{r}_{\mathrm{OP}, \max }$ correspond to the performance measure, the weight of the OP factor and the maximum value of oil production, respectively.

In the second term of the equation, the rest of the factors are evaluated, $r_{i}$ corresponds to the performance measure of the $i_{\text {th }}$ factor, $w_{i}$ is the weight of the $i_{\text {th }}$ factor and $r_{i, \max }$ and $r_{i, \min }$ are the maximum and minimum value of $r_{i}$, respectively.

Each factor makes a different contribution to the total evaluation of the main performance indicator ASM. The Analytic Hierarchy Process (AHP) (Saaty, 2008), was used to calculate the corresponding weight of each factor. This method consists of creating a square matrix based on a pairwise comparison of the factors. The values that indicate how many times one factor is more relevant than the other are according to Saaty's scale. Finally, the matrix entries satisfy the condition $a_{i, j}=1 / a_{j, i}$.

Table 1 shows the pairwise comparison matrix for the factors that constitute the main performance indicator. The final priorities associated with each factor (Table 1) correspond to the priority vector of the pairwise comparison matrix, which is the normalized principal eigenvector of the matrix (Brunelli, 2015).

\subsection{Specific example of effective evaluation methods for simulator learning}

The scenarios must be related to the tasks that the students are going to develop during the first part of the simulation module. The goal is to gradually increase the difficulty of the tasks within the same contexts. In the first part of the module, the students make changes in the system themselves and evaluate the results. In the second part, they are not going to make the changes but to recognize them and solve them. 
Table 1. Pairwise comparison matrix for weighing the factors that constitute the main performance indicator.

\begin{tabular}{|l|c|c|c|c|c|c|c|}
\hline $\begin{array}{l}\text { Pairwise } \\
\text { Assessment }\end{array}$ & ET & OP & EI & EE & AA & CO & Priorities \\
\hline $\begin{array}{l}\text { Effectivity of } \\
\text { Trainee (ET) }\end{array}$ & 1 & $1 / 4$ & $1 / 3$ & $1 / 3$ & $1 / 2$ & $1 / 2$ & 0.063 \\
\hline $\begin{array}{l}\text { Oil Production } \\
\text { (OP) }\end{array}$ & 4 & 1 & 1 & 1 & 3 & 3 & 0.262 \\
\hline $\begin{array}{l}\text { Environmental } \\
\text { Indicator (EI) }\end{array}$ & 3 & 1 & 1 & 1 & 3 & 3 & 0.251 \\
\hline $\begin{array}{l}\text { Energy } \\
\text { Efficiency } \\
\text { (EE) }\end{array}$ & 3 & 1 & 1 & 1 & 2 & 2 & 0.218 \\
\hline $\begin{array}{l}\text { Alarm } \\
\text { Activations } \\
\text { (AA) }\end{array}$ & 2 & $1 / 3$ & $1 / 3$ & $1 / 2$ & 1 & $1 / 2$ & 0.091 \\
\hline $\begin{array}{l}\text { Control } \\
\text { Objectives } \\
\text { (CO) }\end{array}$ & 2 & $1 / 3$ & $1 / 3$ & $1 / 2$ & 2 & 1 & 0.115 \\
\hline
\end{tabular}

For example, one of the tasks of the first part of the module consists of producing a failure in the level controller of the HP separator by changing the controller to manual mode and decreasing the controller output. As a result, the level in the separator increases and reaches the High-High level, which activates the security alarm, and a partial shutdown occurs. The corresponding assessment scenario will also be based on a controller failure, but the students will not know this in advance. The student will have to run the simulation and observe the system behavior, identify the alarm and solve the problem.

In this particular case, the level will reach the High limit, and it will then stabilize for a moment before reaching the High level again. These kinds of scenarios are also devised with the aim of developing the students' situation awareness, since they must be attentive to recognize the changes in the system.

An example is presented below to demonstrate how to apply the Analytic Hierarchy Process together with (1) to calculate the result of the main performance indicator. The results presented below correspond to a trial test executed by the authors.

As mentioned before, the scenario consists of a failure in the level controller of the HP separator. When the scenario starts, the controller mode switches from auto to manual and the controller output is decreased until the level in the separator reaches the High Level Alarm, then the controller output increases again until the level inside the tank reaches a safe value. This sequence is constantly repeated until the problem is solved, as shown in Figure 3. The solution is simply to switch the controller back to auto. Since no controller tuning is required in this scenario, and the abnormal situation does not affect any environmental aspects of the process, these two factors are not considered in the pairwise comparison matrix developed for the example, which is shown in Table 2.

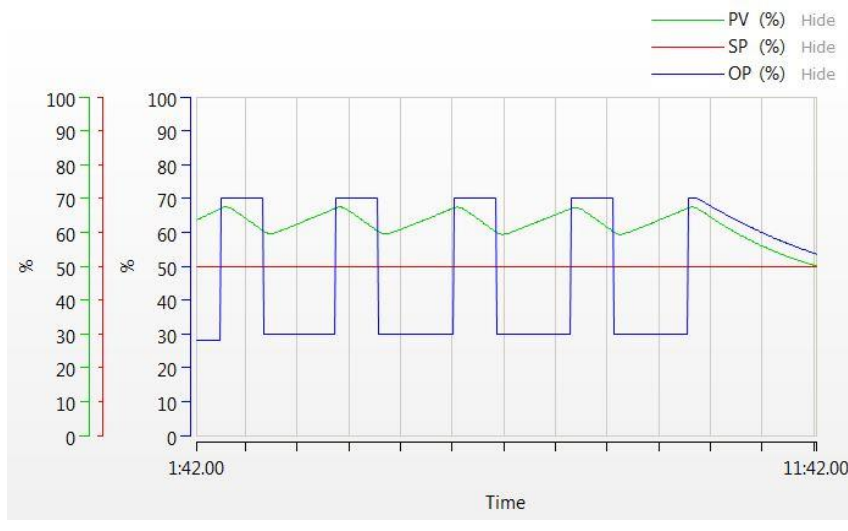

Figure 3. Level controller behavior during the simulation scenario.

Table 2. Pairwise comparison matrix for the example of the level controller failure.

\begin{tabular}{|c|c|c|c|c|}
\hline $\begin{array}{c}\text { Pairwise } \\
\text { Assessment }\end{array}$ & ET & OP & AA & Priorities \\
\hline ET & 1 & $1 / 4$ & $1 / 2$ & 0.137 \\
\hline OP & 4 & 1 & 3 & 0.625 \\
\hline AA & 2 & $1 / 3$ & 1 & 0.239 \\
\hline
\end{tabular}

Table 3 shows the values needed for the calculation of each term of (1), and the final calculation of the main performance indicator that correspond to this example. Table 3 also shows the contribution made by each factor to the final value of the Main Performance Indicator. The example was solved in $11.7 \mathrm{~min}$. The minimum time was $5 \mathrm{~min}$ and the maximum time was $20 \mathrm{~min}$. There were five alarm activations. In this case, the minimum alarm activations was 2 and the maximum was 10 . Finally, the average oil production during the total running period of the example was $908.3 \mathrm{~m}^{3} / \mathrm{h}$ and the maximum production under normal circumstances is approximately $980.0 \mathrm{~m}^{3} / \mathrm{h}$. The sum of the values obtained for each factor multiplied correspondingly by their individual contribution gives a final performance of $80 \%$.

Table 3. Calculation of the final value of the main performance indicator.

\begin{tabular}{|c|c|c|c|c|c|}
\hline & $r_{i}$ & $r_{i, \min }$ & $r_{i, \max }$ & $w_{i}$ & $\begin{array}{c}\text { Equation } \\
\text { Term }\end{array}$ \\
\hline $\begin{array}{c}\mathrm{ET} \\
{[\mathrm{min}]}\end{array}$ & 11.7 & 5.0 & 20.0 & 0.137 & 0.076 \\
\hline AA [-] & 5 & 2 & 10 & 0.239 & 0.149 \\
\hline $\begin{array}{c}\text { OP } \\
{\left[\mathrm{m}^{3} / \mathrm{h}\right]}\end{array}$ & 908.3 & - & 980.0 & 0.625 & 0.579 \\
\hline \multicolumn{5}{|c|}{ Main Performance Indicator } & 0.804 \\
\hline
\end{tabular}




\section{Conclusions}

The simulator training at HiOA currently lacks quick, individual feedback for the participants, and the learning outcomes of the simulator training are not properly assessed after the simulator course. The formal final exam results from HiOA reveal that in spite of the debriefing-workshop after simulator training sessions, some misconceptions remain.

An automatic assessment method is proposed that gives immediate feedback to the students after a scenario is run. The method is based on the evaluation of a main performance indicator that consists of different factors related to the functioning of the process. This main indicator comprises an overall evaluation of the students' progress while dealing with an abnormal situation in the process. The students will receive early and individual feedback on their performance before the workshop, which means they will be able to recognize where there is room for improvement and have the opportunity to work on this before the final exam. Since the instructor will have access to the scenario results of each student, this will also provide the instructor with a clearer picture of how effective the simulator training has been.

The proposed assessment method will be tested at HiOA during the spring and fall semesters of 2017, for the undergraduate courses on chemical engineering and dynamic systems.

\section{Acknowledgements}

The authors would like to thank all the participants in the study and the industrial partner Kongsberg Oil \& Gas Technologies for providing the software and guidance. Docent Finn Aakre Haugen and Professor Arne Ronny Sannerud are also greatly acknowledged for reviewing the draft paper. Last but not least, thanks to the research funder Oslo and Akershus University College of Applied Sciences, Faculty for Technology, Art and Design.

\section{References}

B. Bjørndal and S. Lieberg. In Nye veier $i$ didaktikken?: En innføring $i$ didaktiske emner og begreper. Oslo: Aschehoug, 1978.

M. Brunelli. Priority vector and consistency. Introduction to the Analytic Hierarchy Process: Springer, 2015

A. Coble, A. Smallbone, A. Bhave, R. Watson, A. Braumann, and M. Kraft. In Delivering authentic experiences for engineering students and professionals through e-labs. IEEE EDUCON 2010 Conference, Madrid, Spain, 2010, pages 1085-1090, 2010. doi: 10.1109/EDUCON.2010.5492454

J. E. Corter, S. K. Esche, C. Chassapis, J. Ma, and J. V. Nickerson. Process and learning outcomes from remotely-operated, simulated, and hands-on student laboratories. Computers \& Education, 57(3):2054-2067, 2011. doi: http://dx.doi.org/10.1016/i.compedu.2011.04.009
T. F. Edgar, B. A. Ogunnaike, and K. R. Muske. A global view of graduate process control education. Computers \& Chemical Engineering, $\quad 30(10-12): 1763-1774, \quad 2006 . \quad$ doi: http://dx.doi.org/10.1016/j.compchemeng.2006.05.013

H. Hiim and E. Hippe. In Laring gjennom opplevelse, forståelse og handling: En studiebok $i$ didaktikk. 2 ed. Oslo: Universitetsforlaget, 1998.

A. Kluge, J. Sauer, K. Schüler, and D. Burkolter. Designing training for process control simulators: a review of empirical findings and current practices. Theoretical Issues in Ergonomics Science, 10(6):489-509, 2009. doi: 10.1080/14639220902982192

T. M. Komulainen. In Integrating commercial process simulators into engineering courses. IFAC Proceedings Volumes, 2013, volume 46, pages 274-279. doi: https://doi.org/10.3182/20130828-3-UK-2039.00061

T. M. Komulainen and R. Sannerud. Survey on simulator training in Norwegian oil \& gas industry. Oslo and Akershus University College, Oslo, volume 4, 2014, Available: https://skriftserien.hioa.no/index.php/skriftserien/article/view/ $\underline{19}$

T. M. Komulainen and T. Løvmo. In Large-Scale Training Simulators for Industry and Academia. In A. R. Kolai, K. Sørensen, and M. P. Nielsen, editors, 55th Conference on Simulation and Modelling, Aalborg, Denmark, 2014, pages 128-137, 2014.

T. M. Komulainen, R. Enemark-Rasmussen, G. Sin, J. P. Fletcher, and D. Cameron. Experiences on dynamic simulation software in chemical engineering education. Education for Chemical Engineers, 7(4):e153-e162, 2012. doi: http://dx.doi.org/10.1016/j.ece.2012.07.003

Kongsberg. K-Spice: A new and powerful dynamic process simulation tool. Available via https://www.kongsberg.com/en/kongsbergdigital/news/2009/june/0625_kpice/ [accessed August 29, 2016].

C. F. Lindberg, S. Tan, J. Yan, and F. Starfelt. Key Performance Indicators Improve Industrial Performance. Energy Procedia, 75:1785-1790, 2015. http://dx.doi.org/10.1016/j.egypro.2015.07.474

D. Manca, S. Nazir, and S. Colombo. Performance Indicators for Training Assessment of Control-Room Operators. Chemical Engineering Transactions, 26:285-290, 2012. doi: 10.3303/CET1226048

D. Manca, S. Nazir, F. Lucernoni, and S. Colombo. Performance Indicators for the Assessment of Industrial Operators. In B. Ian David Lockhart and F. Michael, editors, Computer Aided Chemical Engineering. Volume 30, pages 1422-1426: Elsevier, 2012. doi: http://dx.doi.org/10.1016/B978-0-44459520-1.50143-3

C. Martin-Villalba, A. Urquia, and S. Dormido. Object-oriented modelling of virtual-labs for education in chemical process control. Computers \& Chemical Engineering, 32(12):31763186, 2008 . doi: http://dx.doi.org/10.1016/j.compchemeng.2008.05.011

S. Nazir, S. Colombo, and D. Manca. The role of Situation Awareness for the Operators of Process Industry. Chemical Engineering Transactions, 26:303-308, 2012. doi: 10.3303/CET1226051

S. Nazir, S. Colombo, and D. Manca. Minimizing the risk in the process industry by using a plant simulator: a novel approach. Chemical Engineering Transactions, 32:109-114, 2013. doi: 10.3303/ACOS1311028 
S. Nazir, A. Kluge, and D. Manca. Automation in Process Industry: Cure or Curse? How can Training Improve Operator's Performance. In P. S. V. Jiří Jaromír Klemeš and L. Peng Yen, editors, Computer Aided Chemical Engineering. Volume 33, pages 889-894: Elsevier, 2014. doi: http://dx.doi.org/10.1016/B978-0-444-63456-6.50149-6

S. Nazir, L. J. Sorensen, K. I. Øvergård, and D. Manca. Impact of training methods on Distributed Situation Awareness of industrial operators. Safety Science, 73:136-145, 2015. doi: http://dx.doi.org/10.1016/j.ssci.2014.11.015

M. G. Rasteiro, L. Ferreira, J. Teixeira, F. P. Bernardo, M. G. Carvalho et al. LABVIRTUAL-A virtual platform to teach chemical processes. Education for Chemical Engineers, 4(1):e9-e19, 2009.

doi:
N. Rutten, W. R. van Joolingen, and J. T. van der Veen. The learning effects of computer simulations in science education. Computers \& Education, 58(1):136-153, 2012. doi: http://dx.doi.org/10.1016/j.compedu.2011.07.017

T. L. Saaty. Decision making with the analytic hierarchy process. International journal of services sciences, 1(1):83-98, 2008.

P. C. Wankat. Integrating the Use of Commercial Simulators into Lecture Courses. Journal of Engineering Education, 91(1):1923, 2002. doi: 10.1002/j.2168-9830.2002.tb00668.x

Y. Zou, L. Zhang, and P. Li. Reliability forecasting for operators' situation assessment in digital nuclear power plant main control room based on dynamic network model. Safety Science, 80:163-169, 2015. doi: 